Check for updates

The BMJ

Cite this as: BMJ 2021;375:n2982 http://dx.doi.org/10.1136/bmi.n2982 Published: 2 December 2021

\title{
Covid-19: GPs need extra staff and capacity to deliver accelerated booster programme, say leaders
}

\section{Gareth lacobucci}

General practice will require extra staff and capacity to offer covid-19 booster vaccines to everyone over the age of 18 by the end of January, primary care leaders have warned.

On 30 November, the UK prime minister Boris Johnson announced a major expansion of the booster programme in response to the emergence of the omicron variant, telling a Downing Street press briefing that the government aimed to offer a booster dose to all UK adults by the end of January.

To help meet the target, NHS England chief executive Amanda Pritchard said that general practices, pharmacies, and other primary care providers in England would be paid £15 per vaccine dose administered between Monday to Saturday (an increase from $€ 12.58$ ) and $€ 20$ for those administered on Sundays or bank holidays until the end of January. They will also be eligible for a $£ 30$ premium for vaccinations delivered to housebound people until the end of December.

NHS England subsequently announced in a letter to practices $^{1}$ that parts of the Quality and Outcomes Framework (QOF) would be suspended until April, with practices' income protected in a similar way to arrangements in 2020-21, to give practices extra capacity to deliver the booster programme. But some QOF indicators will continue to be paid on the basis of practice performance, including those covering vaccination, cervical screening, register indicators, and those related to optimal prescribing.

Farah Jameel, chair of the BMA's General Practitioners Committee, said, “At present, practices physically don't have the staff or spare capacity to manage the additional numbers of patients expected to come forward for boosters alongside all the non-covid care and assessments their contracts have bound them to do, so the funding, while welcome, will do little to help alleviate current pressures.

"We hope that, by removing some of the more bureaucratic and target based requirements within practices' contracts, staff time can be freed up to get more jabs into arms, while allowing practices to focus on patients who need their attention the most."

To help free up capacity, Pritchard also said that the Care Quality Commission had agreed to continue its pause on routine inspections of general practice in England, while NHS England is examining whether it can "safely reduce or even eliminate" the 15 minute wait after the vaccine is delivered.

The acceleration of the booster programme was announced after the Joint Committee on Vaccination and Immunisation updated its advice ${ }^{2}$ to halve the recommended gap between second doses and boosters to three months. In England alone, this means that almost 14 million more adults will now be eligible for a booster.

Gary Howsam, vice chair of the Royal College of General Practitioners, said that more than 1000 GP led sites across the country were still doing covid vaccinations on top of other work, and he highlighted the need to reduce workload.

"Further involvement in the booster campaign will require sufficient resourcing, particularly in terms of staff, and support to manage escalating workload-including the suspension of bureaucratic demands, such as QOF-as we approach what is looking like an incredibly tough winter," Howsam said.

Joe McManners, a GP in Oxford and clinical director of a local primary care network, told The BMJ that expanding the booster programme would be "very challenging" for primary care given winter pressures and high demand.

"It doesn't help that parts of the media, the government, and elements of NHS England have combined to create a toxic environment for general practice, forgetting the major role we have played throughout the pandemic," he added. "We feel we have been badly treated, then asked for a favour. That said, teams are gearing up for another push, and are keen to do what we can as we recognise the benefit to our patients."

\section{Correction: We updated this story on 6 December 2021 to reflect NHS England's letter to practices stipulating that parts of the Quality and Outcomes Framework would be suspended until April. We also corrected a misspelling of Amanda Pritchard's name in the first instance. \\ NHS England. Letter: JCVI advice in response to the emergence of the B.1.1.529 (Omicron) variant: next steps for deployment. 3 Dec 2021 https://www.england.nhs.uk/coronavirus/wp-content/up- loads/sites/52/2021/12/C1468-jvci-advice-in-response-to-the-emergence- of-the-b.1.1.529-omicron-variant-next-steps-for-deployment.pdf \\ 2 UK Health Security Agency. JCVI advice on covid-19 booster vaccines for those aged 18 to 39 and a second dose for ages 12 to 15.29 Nov 2021. www.gov.uk/government/news/icvi-advice-on-covid-19-booster-vaccines- for-those-aged-18-to-39-and-a-second-dose-for-ages-12-to-15}

This article is made freely available for use in accordance with BMJ's website terms and conditions for the duration of the covid-19 pandemic or until otherwise determined by BMJ. You may use, download and print the article for any lawful, non-commercial purpose (including text and data mining) provided that all copyright notices and trade marks are retained. 